\title{
Applied Technique for Utilizing Total Station in Monitoring Differential Settlement
}

\author{
${ }^{* 1}$ Mohammed Aldelgawy \\ ${ }^{* 1}$ Faculty of Hijjawi for Engineering Technology, Civil Engineering Department, Yarmouk University, Irbid, Jordan \\ ${ }^{* 1}$ Faculty of Engineering, Civil Engineering Department, Fayoum University, Fayoum, Egypt
}

\begin{abstract}
Recently, many problems regarding differential settlement for newly constructed buildings in Fayoum city, Egypt have been monitored. This research presents an applied technique for utilizing total station in observing horizontal and vertical movements happening by time for some building in Fayoum city. The building was monitored for thirty three months divided into three phases. In the first phase, façade of building was observed for four and half months to monitor differential settlement and take the right decision for resolving differential settlement problem. The second phase was the execution of that decision. Time for second phase was four and half months. Finally, in the third phase façade of building was reobserved for two years in order to make sure that the movement of façade points was stopped. The obtained results showed that the used technique provided a powerful and efficient tool to observe movements of façade points by time.
\end{abstract}

Key words: Total station, laser observation, differential settlement monitoring, land surveying, total station errors

\section{Introduction}

Problems regarding the newly constructed buildings have been frequently monitored in Fayoum city, Egypt. The most critical one of these problems is the differential settlement of these new buildings. The reason behind that differential settlement is these new buildings were constructed rapidly and randomly without making the enough study for the soil of construction lying underneath these buildings. Accordingly, the used type of foundation and depth of construction was inappropriate. Monitoring the behavior of these new buildings by time was urgent necessity in order to make the right decision to resolve the settlement problem. The monitoring process was performed utilizing total station instrument as it observes the point coordinates in the 3D space. Nevertheless, traditional technique used in mapping surveying does not provide the precision required for such application. In mapping surveying work, the orientation of horizontal coordinates in field is done either by making zero-set for the horizontal circle of total station instrument or by making backsight process [5]. However, for higher level of precision, this technique is not the most adequate one.

Kaloop et al [4] presented two different surveying techniques (one and two total stations measurement techniques) to evaluate the deformation behavior of structural members. Thomas [9] introduced a technique of prism monitoring for mining slope stability depending on establishing reference network consists of number of reference beacons. The objective was to measure the movement of selected point per day. Afeni and Cawood [1] discussed various challenges likely to be encountered during slope stability monitoring using a total station and possible ways to overcome them. The authors showed that a robotic total station system should be complemented by other monitoring techniques such as GPS, radar and/or laser scanning, and geotechnical instrumentation e.g. piezometer and extensometer.

*Corresponding Author: Mohammed Aldelgawy: Address: Faculty of Hijjawi for Engineering, Department of Civil Engineering Yarmouk University, Irbid, JORDAN. E-mail address: mas00@fayou.edu.eg, Phone: +962786876593 
In this research, a modified technique for observing points utilizing total station instrument was developed. This technique is illustrated in details in the following section. Then, the used mathematical approach for calculating the coordinates of the observed points along with their expected errors is introduced. Afterwards, the experimental work is illustrated. Finally, the conclusion and recommendations of the future work are introduced at the end of the research.

\section{Technique User for Observation}

A modified technique for observing points is used in this research. This technique relies on monitoring the same points at different dates. Each date was named as monitoring date. Moreover, the first monitoring date was named as day zero. Observations at day zero were considered as the datum of observations for all other monitoring dates. At each monitoring date (including day zero), two sets of points were observed. The first set of observed points was a number of selected points on the façade of building under study. Sheet prisms were attached to these façade points. On the other hand, the second set of points was two reference points. Reference point is that point which is fixed (not expected to move) during the whole duration of the study. Reference points were selected in the neighborhood out of the building in question and sheet prisms were attached to them. The line connecting the two reference points was named as reference line. At each monitoring date (including day zero), both façade points and reference points were observed from the same station point and the north direction was assigned utilizing a compass.

In order to relate coordinate system at each monitoring date to that at day zero, they need to be measured with respect to (WRT) the same origin and with the same horizontal and vertical orientations. However the station point at each monitoring date is the same, the difference in centering error at each observation time affects the precision of the final results. In addition, the small difference in north direction assigned by compass each time affects the overall precision as well. Even if the north direction is assigned at each monitoring date in ordinary method using backsight technique, the required precision will not be achieved. Furthermore, the error in assigning the height of instrument to measure the vertical coordinates exceeds the required precision of observations. As a result, the coordinate system at each monitoring date is different from each other. However, coordinate systems at each monitoring date should be precisely transformed to that at day zero (since day zero represents the datum for observations at all other monitoring dates).

Coordinates of any point observed by total station instrument consists of vertical coordinate and horizontal coordinates (east and north coordinates). In order to transform vertical coordinate system at any monitoring date to that at day zero, the difference between vertical coordinate of the first reference point observed at day zero and its conjugate vertical coordinate observed at this monitoring date was computed. Then, this difference was added to the vertical coordinate of all points observed at the monitoring date in question. On the other hand, the horizontal coordinate system at any monitoring date was transformed to that at day zero. This was done by aligning the reference line at this monitoring date to the conjugate reference line at day zero using the first reference point as a base point. In other words, the difference between horizontal coordinates of the first reference point observed at day zero and its conjugate horizontal coordinates observed at monitoring date in question was computed. This difference was added to all horizontal coordinates of all points observed at the monitoring date in question. Afterwards, the horizontal angle between the reference line at day zero and the conjugate reference line at the required monitoring date was computed. Then, horizontal coordinates of all points observed at the monitoring date in purpose were rotated by this computed horizontal angle.

Differences between the transformed vertical and horizontal coordinates of all point observed at any monitoring date and their conjugate coordinates observed at day zero were computed. These differences 
represent the movement happened to points observed at this monitoring date relative to their positions at day zero. In order to obtain meaningful results, the computed horizontal differences were analyzed to two components parallel and perpendicular to the façade direction observed at day zero. In addition, the expected random errors of the values of these differences were computed. Computing the values of expected random errors is very significant in order to differentiate between the difference in coordinates due to random errors and the difference due to real movement of the façade point(s). Since observations were made accurately and expertly, the systematic errors were neglected.

\section{Mathematical Approach}

Difference in vertical and horizontal positions for each observed façade point at each monitoring date WRT its position observed at day zero is computed in four steps. The first step is to calculate the 3D rectangular coordinates of points observed at all monitoring dates (including day zero). The second step is to calculate difference in vertical positions for points observed at any monitoring date WRT their conjugate positions at day zero. Whereas, the third step is to calculate difference in horizontal positions (in both east and north directions) for points observed at any monitoring date WRT their conjugate positions at day zero. Finally, the fourth step is to analyze this horizontal difference in horizontal position for each point into two components parallel and perpendicular to the façade direction observed at day zero. These four steps along with resulted random errors in calculated quantities in each step are illustrated in the following subsections.

\subsection{Three-dimensional rectangular coordinates of observed point:}

For any observed point, the mathematical formulae which represent the relationship between the input observations and the output 3D rectangular coordinates of this point are as follows [10]:

$E=E_{O}+S \cdot \operatorname{Cos} v \cdot \operatorname{Sin} \alpha$

$N=N_{O}+S \cdot \operatorname{Cos} v \cdot \operatorname{Cos} \alpha$

$Z=Z_{O}+h_{O}-h_{t}+S \cdot \operatorname{Sin} v$

; Where: $(E, N, Z)$ and $\left(E_{O}, N_{O}, Z_{O}\right)$ are the $3 \mathrm{D}$ rectangular coordinates (east, north, vertical coordinates) for both observed point and station point, respectively,

$(S, \alpha, v)$ are distance, horizontal azimuth angle, and vertical angle measured by the total station instrument for observed point, respectively,

$\left(h_{O}, h_{t}\right)$ are the height of total station instrument and the target (prism) height, respectively.

Since the target is sheet prism, the target height $\left(h_{t}\right)$ is equal to zero. Accordingly,

$Z=Z_{O}+h_{O}+S \cdot \operatorname{Sin} v$

Differences in both vertical and horizontal positions of points are calculated relative to reference points. Accordingly, the value of station coordinates and height of total station instrument does not affect the final value of these differences. Consequently, the error for station coordinates and instrument height are equal to zero. As a result, applying the error propagation rule [6] to equations $(1,2$, and 4$)$ to find the expected random errors in the rectangular coordinates leads to:

$\sigma_{E}=\sqrt{\begin{array}{c}\left(\frac{E-E_{O}}{S}\right)^{2} \cdot \sigma_{S}^{2}+\left(N-N_{O}\right)^{2} \cdot \sigma_{\alpha}^{2} \\ +\left(\left(E-E_{O}\right) \cdot \operatorname{Tan} v\right)^{2} \cdot \sigma_{v}^{2}\end{array}}$ 
$\sigma_{N}=\sqrt{\begin{array}{l}\left(\frac{N-N_{O}}{S}\right)^{2} \cdot \sigma_{S}^{2}+\left(E-E_{O}\right)^{2} \cdot \sigma_{\alpha}^{2} \\ +\left(\left(N-N_{O}\right) \cdot \operatorname{Tan} v\right)^{2} \cdot \sigma_{v}^{2}\end{array}}$
$\sigma_{Z}=\sqrt{(\operatorname{Sin} v)^{2} \cdot \sigma_{S}^{2}+(S \cdot \operatorname{Cos} v)^{2} \cdot \sigma_{v}^{2}}$

; Where: $\left(\sigma_{E}, \sigma_{N}, \sigma_{Z}\right)$ are the expected random errors in the east, north, and vertical coordinate of the observed point, respectively, and

$\left(\sigma_{S}, \sigma_{\alpha}, \sigma_{v}\right)$ are the errors in measuring distance $(S)$, horizontal angle $(\alpha)$, and vertical angle $(v)$, respectively.

\subsection{Difference in vertical positions for points observed at monitoring date (i) WRT their conjugate positions at day zero:}

The difference $\left(\Delta Z_{(i)}\right)$ between vertical position of any point observed at monitoring date (i) and its conjugate position observed at day zero is computed as follows:

$\Delta Z_{(i)}=Z_{R 1(0)}-Z_{R 1(i)}-Z_{(0)}+Z_{(i)}$

; Where: $\left(Z_{R 1(0)}, Z_{(0)}\right)$ are vertical coordinates of the first reference point and the point in question observed at day zero WRT coordinate system of day zero, respectively, and $\left(Z_{R 1(i)}, Z_{(i)}\right)$ are vertical coordinates of the first reference point and the point in question observed at monitoring date (i) WRT coordinate system of this monitoring date, respectively.

Applying the error propagation rule to equation (8), then the expected random error $\left(\sigma_{\Delta Z(i)}\right)$ for difference $\left(\Delta Z_{(i)}\right)$ in vertical position of any point is:

$\sigma_{\Delta Z(i)}=\sqrt{\sigma_{Z R 1(0)}^{2}+\sigma_{Z R 1(i)}^{2}+\sigma_{Z(0)}^{2}+\sigma_{Z(i)}^{2}}$

;Where: $\left(\sigma_{\mathrm{ZR} 1(0)}, \sigma_{\mathrm{ZR} 1(\mathrm{i})}, \sigma_{\mathrm{Z}(0)}, \sigma_{\mathrm{Z}(\mathrm{i})}\right)$ are $\quad$ expected random errors in coordinates $\left(\mathrm{Z}_{\mathrm{R} 1(0)}, \mathrm{Z}_{\mathrm{R} 1(\mathrm{i})}, \mathrm{Z}_{(0)}, \mathrm{Z}_{(\mathrm{i})}\right)$, respectively, calculated applying equation (7).

3.3. Difference in horizontal positions (east, north) for points observed at monitoring date (i) WRT their conjugate positions at day zero:

\subsubsection{Rotational angle required to transform from coordinate system at monitoring date (i) to coordinate system at day zero:}

First of all, angle $\left(\theta_{i}\right)$ between the reference line and the horizontal axis in east direction $\left(E_{(i)}\right)$ at monitoring date (i) is computed as follows (Figure 1):

$\theta_{i}=\operatorname{Tan}^{-1}\left(\frac{N_{R 2(i)}-N_{R 1(i)}}{E_{R 2(i)}-E_{R 1(i)}}\right)$

; Where: $\left(E_{R 1(i)}, N_{R 1(i)}\right),\left(E_{R 2(i)}, N_{R 2(i)}\right)$ are horizontal coordinates of the first and second reference points WRT coordinate system at monitoring date (i), respectively. 


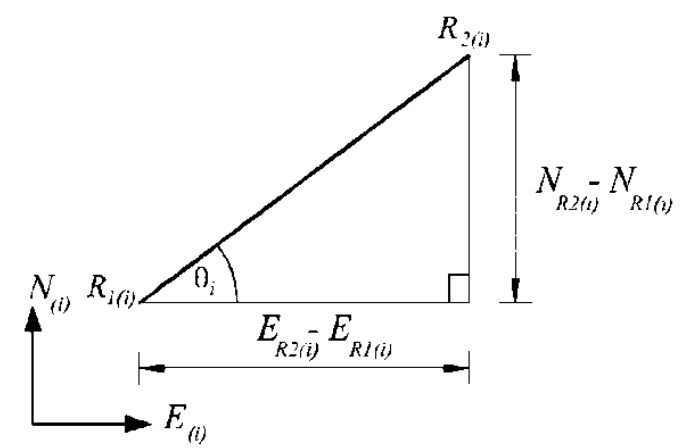

Figure 1. Rotational Angle $\left(\theta_{\mathrm{i}}\right)$ Between Reference Line and East Direction $\left(\mathrm{E}_{(\mathrm{i})}\right)$ at Monitoring Date (i)

Then, expected random error $\left(\sigma_{\theta(i)}\right)$ for horizontal angle $\left(\theta_{i}\right)$ is:

$\sigma_{\theta(i)}=\frac{1}{D_{(i)}} \sqrt{\begin{array}{c}\left(\sigma_{E R 1(i)}^{2}+\sigma_{E R 2(i)}^{2}\right) \cdot \operatorname{Sin}^{2} \theta_{i} \\ +\left(\sigma_{N R 1(i)}^{2}+\sigma_{N R 2(i)}^{2}\right) \cdot \operatorname{Cos}^{2} \theta_{i}\end{array}}$

; Where: $\left(\sigma_{E R 1(i)}, \sigma_{N R 1(i)}\right),\left(\sigma_{E R 2(i)}, \sigma_{N R 2(i)}\right)$ are the random errors of horizontal coordinates of the first and second reference points WRT coordinate system at monitoring date (i), respectively, calculated applying equations (5) and (6), and

$D_{(i)}$ is the horizontal distance between the first and second reference points $(R 1, R 2)$ observed at monitoring date (i):

$D_{(i)}=\sqrt{\left(N_{R 2(i)}-N_{R 1(i)}\right)^{2}+\left(E_{R 2(i)}-E_{R 1(i)}\right)^{2}}$

Similarly, angle $\left(\theta_{0}\right)$ between the reference line and the horizontal axis in east direction $\left(E_{(0)}\right)$ at day zero besides the expected random error $\left(\sigma_{\theta(0)}\right)$ in this angle is computed.

Accordingly, the rotational angle $\left(\emptyset_{i}\right)$ required to transform from horizontal coordinate system at monitoring date (i) to horizontal coordinate system at day zero is:

$\emptyset_{i}=\theta_{0}-\theta_{i}$

Then, the expected random error $\left(\sigma_{\emptyset(i)}\right)$ for horizontal angle $\left(\emptyset_{i}\right)$ is:

$\sigma_{\varnothing(i)}=\sqrt{\sigma_{\theta(0)}^{2}+\sigma_{\theta(i)}^{2}}$

\subsubsection{Difference in horizontal position for any observed point:}

To calculate difference in horizontal position for any point observed at monitoring date (i) WRT its conjugate position at day zero, the following $2 \mathrm{D}$ transformation formulae [3] are used:

$\Delta E_{(i)}=E_{R 1(0)}-E_{(0)}+\left(E_{(i)}-E_{R 1(i)}\right) \operatorname{Cos} \emptyset_{i}$

$+\left(N_{(i)}-N_{R 1(i)}\right) \operatorname{Sin} \emptyset_{i}$

$\Delta N_{(i)}=N_{R 1(0)}-N_{(0)}-\left(E_{(i)}-E_{R 1(i)}\right) \operatorname{Sin} \emptyset_{i}$ $+\left(N_{(i)}-N_{R 1(i)}\right) \operatorname{Cos} \emptyset_{i}$

; Where: $\left(\Delta E_{(i)}, \Delta N_{(i)}\right)$ are differences in horizontal position for point observed at monitoring date (i) WRT east and north directions assigned at day zero,

$\left(E_{R 1(i)}, N_{R 1(i)}\right)$ and $\left(E_{(i)}, N_{(i)}\right)$ are horizontal coordinates of the first reference point and the point in question observed at monitoring date (i) WRT coordinate system at monitoring date (i), respectively,

$\left(E_{R 1(0)}, N_{R 1(0)}\right)$ and $\left(E_{(0)}, N_{(0)}\right)$ are the horizontal coordinates of the first reference point and the point in question observed at day zero WRT coordinate system at day zero, respectively. 
Then, the expected random errors $\left(\sigma_{\Delta E(i)}, \sigma_{\Delta N(i)}\right)$ in differences $\left(\Delta E_{(i)}, \Delta N_{(i)}\right)$, respectively, are:

$$
\sigma_{\Delta E(i)}=\sqrt[\begin{array}{c}
\sigma_{E R 1(0)}^{2}+\sigma_{E(0)}^{2}+\left(\sigma_{E R 1(i)}^{2}+\sigma_{E(i)}^{2}\right) \cdot \operatorname{Cos}^{2} \emptyset_{i}+ \\
\left(\sigma_{N R 1(i)}^{2}+\sigma_{N(i)}^{2}\right) \cdot \operatorname{Sin}^{2} \emptyset_{i}+ \\
\left(\left(E_{(i)}-E_{R 1(i)}\right) \operatorname{Sin} \emptyset_{i}-\left(N_{(i)}-N_{R 1(i)}\right) \operatorname{Cos} \emptyset_{i}\right)^{2} \sigma_{\emptyset(i)}^{2}
\end{array}]{\sigma_{\Delta N(i)}=\sqrt{\begin{array}{c}
\sigma_{N R 1(0)}^{2}+\sigma_{N(0)}^{2}+\left(\sigma_{E R 1(i)}^{2}+\sigma_{E(i)}^{2}\right) \cdot \operatorname{Sin}^{2} \emptyset_{i}+ \\
\left(\sigma_{N R 1(i)}^{2}+\sigma_{N(i)}^{2}\right) \cdot \operatorname{Cos}^{2} \emptyset_{i}+ \\
\left(\left(E_{(i)}-E_{R 1(i)}\right) \operatorname{Cos} \emptyset_{i}+\left(N_{(i)}-N_{R 1(i)}\right) \operatorname{Sin} \emptyset_{i}\right)^{2} \sigma_{\emptyset(i)}^{2}
\end{array}}}
$$

; Where: $\left(\sigma_{E R 1(0)}, \sigma_{E R 1(i)}, \sigma_{E(0)}, \sigma_{E(i)}\right)$ are the expected random errors in east coordinates $\left(E_{R 1(0)}, E_{R 1(i)}, E_{(0)}, E_{(i)}\right)$ respectively, calculated applying equation (5), and $\left(\sigma_{N R 1(0)}, \sigma_{N R 1(i)}, \sigma_{N(0)}, \sigma_{N(i)}\right)$ are the expected random errors in north coordinates $\left(N_{R 1(0)}, N_{R 1(i)}, N_{(0)}, N_{(i)}\right)$, respectively, calculated applying equation (6).

\subsection{Components parallel and perpendicular to façade direction observed at day zero:}

Façade points are selected such that each monitored floor of building under study contains two façade points. At any floor, angle $\left(\beta_{12(0)}\right)$ is the angle between façade line $\left(\mathrm{P}_{1(0)} \mathrm{P}_{2(0)}\right)$ and the horizontal axis in east direction $\left(E_{(0)}\right)$ at day zero (Figure 2). In addition, the horizontal axes $\left(X_{12(0)}\right)$ and $\left(Y_{12(0)}\right)$ are selected parallel and perpendicular to façade line $\left(\mathrm{P}_{1(0)} \mathrm{P}_{2(0)}\right)$, respectively. The angle $\left(\beta_{12(0)}\right)$ is computed as follows:

$\beta_{12(0)}=\operatorname{Tan}^{-1}\left(\frac{N_{P 2(0)}-N_{P 1(0)}}{E_{P 2(0)}-E_{P 1(0)}}\right)$

; Where: $\left(E_{P 1(0)}, N_{P 1(0)}\right),\left(E_{P 2(0)}, N_{P 2(0)}\right)$ are horizontal coordinates of façade points $\left(\mathrm{P}_{1(0)}\right)$ and $\left(\mathrm{P}_{2(0)}\right)$ WRT coordinate system at date zero, respectively,

Expected random error $\left(\sigma_{\beta 12(0)}\right)$ for horizontal angle $\left(\beta_{12(0)}\right)$ is:

$\sigma_{\beta 12(0)}=\frac{1}{D_{12(0)}} \sqrt{\begin{array}{c}\left(\sigma_{E P 1(0)}^{2}+\sigma_{E P 2(0)}^{2}\right) \cdot \operatorname{Sin}^{2} \beta_{12(0)} \\ +\left(\sigma_{N P 1(0)}^{2}+\sigma_{N P 2(0)}^{2}\right) \cdot \operatorname{Cos}^{2} \beta_{12(0)}\end{array}}$

; Where: $\left(\sigma_{E P 1(0)}, \sigma_{N P 1(0)}\right),\left(\sigma_{E P 2(0)}, \sigma_{N P 2(0)}\right)$ are the random errors of horizontal coordinates of the first and second reference points, respectively, WRT coordinate system at day zero calculated applying equations (5) and (6), and

$D_{12(0)}$ is the horizontal distance $\left(\mathrm{P}_{1(0)} \mathrm{P}_{2(0)}\right)$ calculated similar to the value calculated in equation (12).

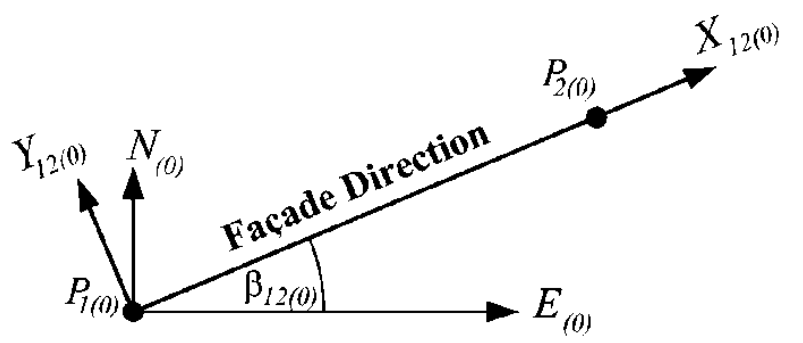

Figure 2. Angle $\left(\beta_{12(0)}\right)$ Between Façade Direction and East Direction $\left(E_{(0)}\right)$ at Day Zero

For any point observed at monitoring date (i), the differences in horizontal positions $\left(\Delta X_{(i)}, \Delta Y_{(i)}\right)$ parallel and perpendicular to façade direction observed at day zero are: 
$\Delta X_{(i)}=\Delta E_{(i)} \operatorname{Cos} \beta_{12(0)}+\Delta N_{(i)} \operatorname{Sin} \beta_{12(0)}$

$\Delta Y_{(i)}=\Delta N_{(i)} \operatorname{Cos} \beta_{12(0)}-\Delta E_{(i)} \operatorname{Sin} \beta_{12(0)}$

Then, the expected random errors $\left(\sigma_{\Delta X(i)}, \sigma_{\Delta Y(i)}\right)$ for the above differences $\left(\Delta X_{(i)}, \Delta Y_{(i)}\right)$ are:

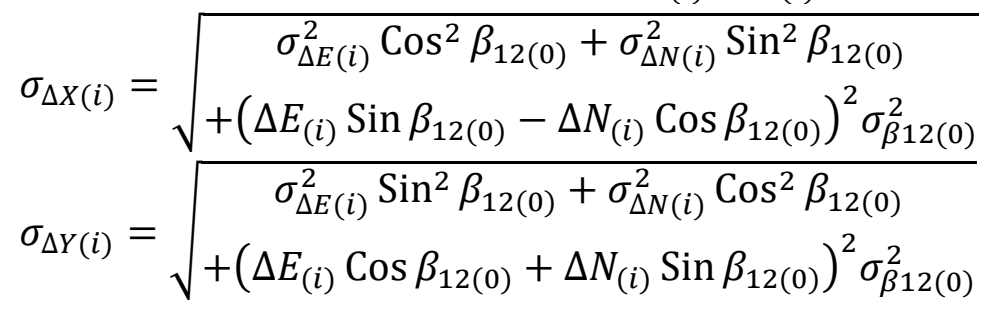

\section{Experimental Work}

In this part of research, experiments were conducted using a calibrated SOKKIA Series 10K SET210K total station instrument. According to the calibration report of total station instrument, values of accuracy of the measured raw data $(S, \alpha, v)$ were taken as follows: $\sigma_{S}(\mathrm{~mm})= \pm(3 \mathrm{~mm}+3 * S(\mathrm{~km})), \sigma_{\alpha}= \pm 5^{\prime \prime}$, $\sigma_{v}= \pm 5 "$. Size of the utilized sheet prisms was $(5 \times 5 \mathrm{~cm})$. Experiments were conducted on some building in Fayoum city, Egypt. This building consists of ground floor in addition to ten floors. The building was supported on 1.20 meters reinforced concrete raft foundation at a construction depth of 4 meters. Façade of this building is shown in Figure 3. The length of this façade was about 14 meters.

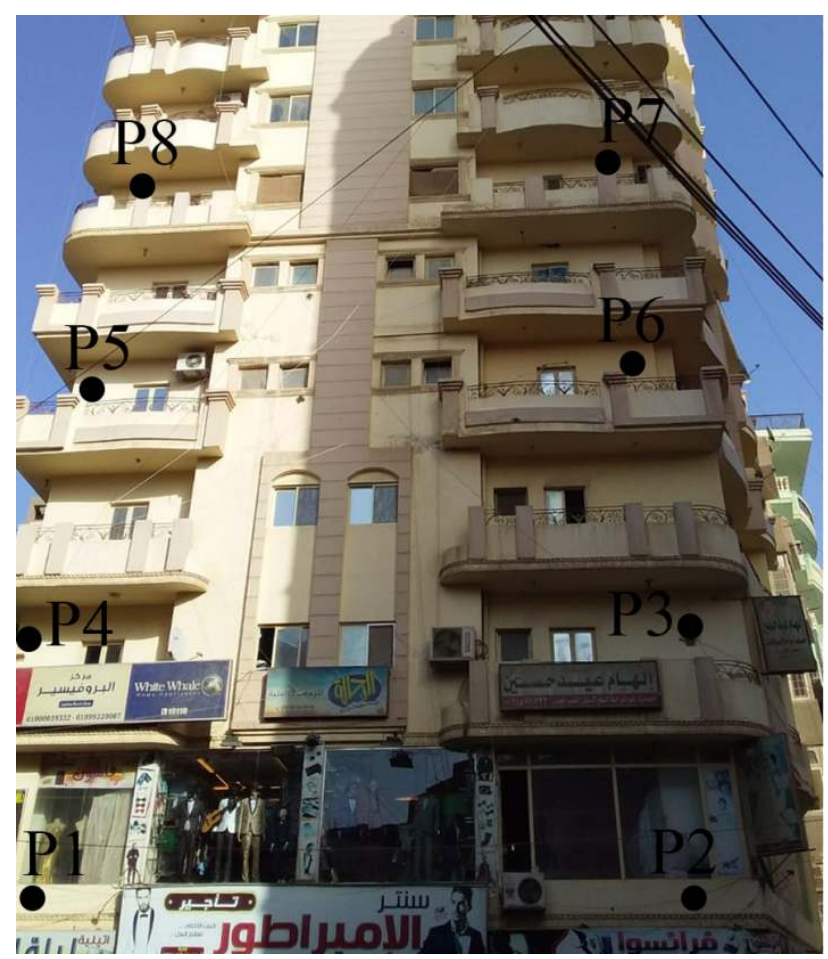

Figure 3. Façade of Building Under Study

A differential settlement happened to building in question before making the study. As a result, the experiments introduced here were demanded in order to study the behavior of building by time and make the right decision to resolve the problem. Eight points were selected on the façade of building and sheet prisms were attached to them (Figure 3). Two points (P1, P2) were selected on the first floor, two points 
(P3, P4) on the second floor, two points (P5, P6) on the fourth floor, and two points (P7, P8) on the sixth floor of building. Moreover, two reference points (R1, R2) were selected out of the building under study in places that is not expected to be changed during the whole time of monitoring. Sheet prisms were attached to these reference points as well. The horizontal coordinate system parallel and perpendicular to façade direction of the first floor observed at day zero is shown in Figure 4. In this figure, the positive ( $X$-axis) is parallel to façade direction to right, while the positive ( $Y$-axis) is to the outward of the building. On the other hand, the positive ( $Z$-axis) is to the upward vertical direction.

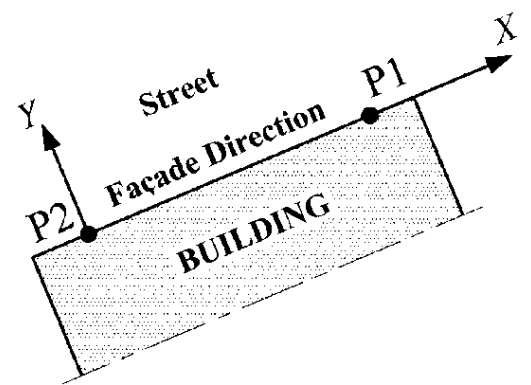

Figure 4. Horizontal Coordinate System Parallel and Perpendicular to Façade Direction for Points (P1) and (P2) at the First Floor of Building

The building under study was monitored for thirty three months divided into three phases. In the first phase, the façade of building was observed for four and half months (eighteen weeks) in order to monitor the differential settlement and take the right decision for recovery. The second phase was the recovery process of building. The time for second phase was four and half months. Finally, in the third phase the façade of building was reobserved for two years in order to make sure that the movement of façade points was stopped and the settlement was prevented. These three phases are illustrated below.

\section{First phase:}

In this phase, experiments were conducted by monitoring the façade of building under study by time in order to study the behavior of the movements happening to façade points. According to this behavior, the proper decision to resolve the differential settlement problem was taken. In addition to day zero, the monitoring dates for this phase were week 1 , week 3 , week 5 , week 7 , week 9 , week 12 , week 14 , and week 18.

Differences in positions $(\Delta X, \Delta Y, \Delta Z)$ relative to day zero at week 18 (the last monitoring date) for the 8 façade points besides the expected random errors for these differences $\left(\sigma_{\Delta X}, \sigma_{\Delta Y}, \sigma_{\Delta Z}\right)$ are illustrated in Table 1. The table shows that no movement happened to all points parallel to façade direction since the value of difference in position for all points in this direction were within the range of expected random errors for these values. Whereas, outward movements of façade points perpendicular to façade direction were monitored (especially for points (P5), (P6), (P7), and (P8)) as differences in positions in this direction exceeded the values of expected random errors. The amounts of these perpendicular movements increase by height. Furthermore, downward vertical movements (settlement) for the 8 façade points were monitored as vertical differences for these points exceeded the expected random errors for these differences. 
Table 1. Results in Millimeters for Façade Points Observed at Week 18 in the First Phase

\begin{tabular}{cccccccc}
\hline \multirow{2}{*}{ Floor } & Point & \multicolumn{2}{c}{$\mathrm{X}-$ Direction } & \multicolumn{2}{c}{$\mathrm{Y}$-Direction } & \multicolumn{2}{c}{$\mathrm{Z}-$ Direction } \\
\cline { 2 - 7 } & & $\Delta \mathrm{X}$ & $\sigma_{\Delta \mathrm{X}}$ & $\Delta \mathrm{Y}$ & $\sigma_{\Delta \mathrm{Y}}$ & $\Delta \mathrm{Z}$ & $\sigma_{\Delta \mathrm{Z}}$ \\
\hline \multirow{2}{*}{1} & P1 & -1.5 & \pm 4.5 & 1.7 & \pm 4.4 & -5.1 & \pm 1.2 \\
& $\mathrm{P} 2$ & -1.6 & \pm 4.6 & 1.4 & \pm 4.2 & -4.9 & \pm 1.2 \\
\multirow{2}{*}{2} & P3 & -2.1 & \pm 4.6 & 3.0 & \pm 4.1 & -6.2 & \pm 1.5 \\
& P4 & -3.5 & \pm 4.4 & 4.1 & \pm 4.3 & -6.1 & \pm 1.5 \\
\multirow{3}{*}{4} & P5 & -3.6 & \pm 4.3 & 4.7 & \pm 4.2 & -6.5 & \pm 2.2 \\
& P6 & -1.5 & \pm 4.5 & 4.9 & \pm 4.0 & -6.8 & \pm 2.2 \\
& P7 & -1.9 & \pm 4.3 & 7.1 & \pm 3.9 & -8.0 & \pm 2.8 \\
& P8 & -2.1 & \pm 4.2 & 7.9 & \pm 4.0 & -7.0 & \pm 2.8 \\
\hline
\end{tabular}

In addition, differences relative to day zero in horizontal positions parallel and perpendicular to façade direction monitored at day zero along with differences in vertical positions for points (P7) and (P8) in the 6th floor are illustrated in Figure 5 and Figure 6, respectively. In these figures, the solid line represents the value of differences in position, while the two dashed lines represent the values of expected errors for these differences. The upper dashed line represents the positive value of expected random error $(+\sigma)$. While, the lower dashed line represents the negative value of expected random error $(-\sigma)$. If the value of difference in position $(\Delta X, \Delta Y$, or $\Delta Z)$ at any monitoring date (lying on the solid line) lies between the two dashed lines, this means that the difference at this monitoring date is within the range of expected random error. Otherwise, this difference represents a real movement of point. The figures show that no significant movement by time happened parallel to façade direction. However, starting from week 9 till week 18, outward movements perpendicular to façade direction in addition to downward vertical movements (settlement) were monitored for both points (P7) and (P8). The amount of movements monitored in both perpendicular to façade direction and vertical direction increased by time.
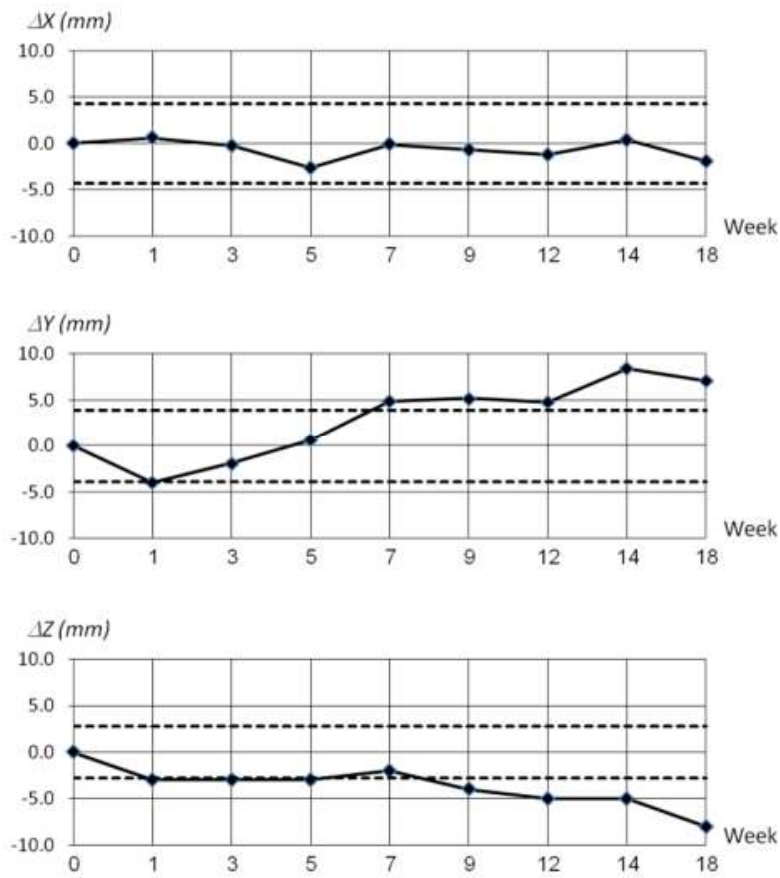

Figure 5. Results in Millimeters for Point (P7) in the 6th Floor in the First Phase 

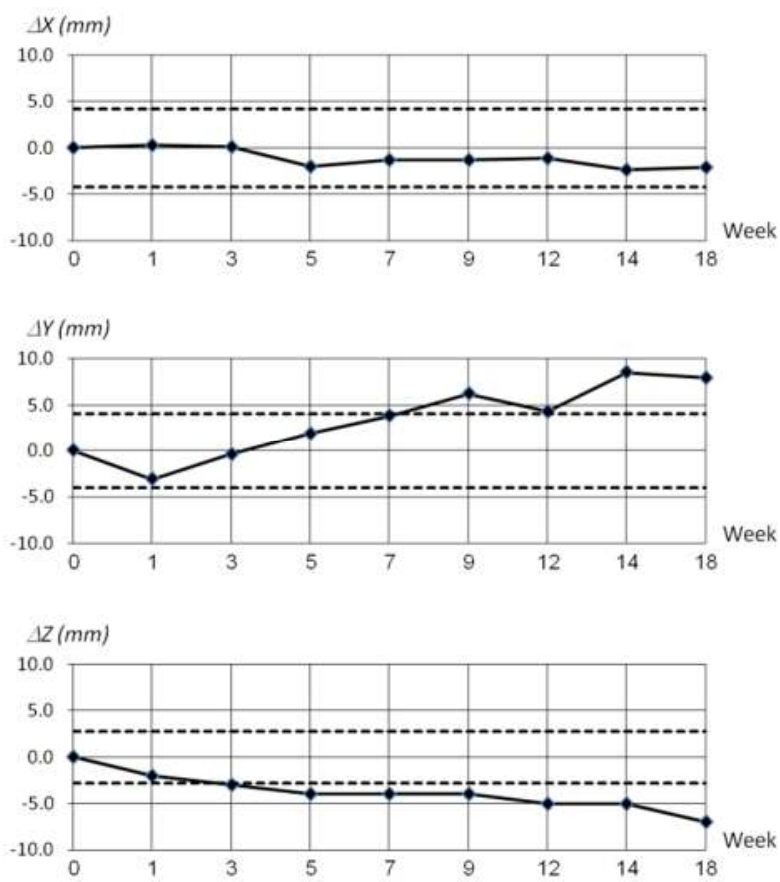

Figure 6. Results in Millimeters for Point (P8) in the 6th Floor in the First Phase

\section{Second phase:}

In this phase, the recovery for building under study was made. As earlier mentioned, the foundation type used in the building was 1.20 meters reinforced concrete raft at a construction depth of 4 meters. Boreholes were made next to the building in question in order to recognize the type of soil layers underneath the building. In addition, structural study for the building was made. According to soil investigation and structural study along with results obtained in the first phase, the recovery decision was made. This decision was to construct sheet piles next to the façade under study of building and connect them to the raft foundation. The diameter of pile was 0.30 meters and the length (depth) of pile was 10 meters. The total number of piles was 25 piles distributed at equal distances along the façade of building. The time taken to study, discuss, decide, and execute the decision was four and half months.

\section{Third phase:}

Experiments were conducted in this phase in order to check the validity and efficiency of the recovery decision executed in the second phase. First, both sets of façade points and reference points were observed at day zero for this phase. Then, the same points were observed at different monitoring dates. The monitoring dates for this phase were week 2, week 6 , week 12 , week 24 , year 1 , and year 2 . During these monitoring dates no significant movements for façade points were observed. Results obtained at year 2 are illustrated at Table 2. The table shows that the values of differences in positions of façade points parallel and perpendicular to façade direction along with vertical direction were within the expected random error for these values. This means that the recovery in the second phase was made successfully and the differential settlement of the building has stopped. 
Table 2. Results in Millimeters for Façade Points Observed at Year 2 in the Third Phase

\begin{tabular}{cccccccc}
\hline \multirow{2}{*}{ Floor } & Point & \multicolumn{2}{c}{$\mathrm{X}$-Direction } & \multicolumn{2}{c}{$\mathrm{Y}$-Direction } & \multicolumn{2}{c}{$\mathrm{Z}$-Direction } \\
\cline { 3 - 7 } & & $\Delta \mathrm{X}$ & $\sigma_{\Delta \mathrm{X}}$ & $\Delta \mathrm{Y}$ & $\sigma_{\Delta \mathrm{Y}}$ & $\Delta \mathrm{Z}$ & $\sigma_{\Delta \mathrm{Z}}$ \\
\hline \multirow{2}{*}{1} & $\mathrm{P} 1$ & -2.3 & \pm 4.5 & -1.4 & \pm 4.4 & -1.8 & \pm 1.2 \\
& $\mathrm{P} 2$ & -1.8 & \pm 4.6 & 1.7 & \pm 4.2 & -2.4 & \pm 1.2 \\
\multirow{2}{*}{2} & P3 & -3.1 & \pm 4.6 & 0.8 & \pm 4.1 & -2.9 & \pm 1.5 \\
& P4 & -3.0 & \pm 4.4 & 0.5 & \pm 4.3 & -2.8 & \pm 1.5 \\
\multirow{3}{*}{4} & P5 & -3.4 & \pm 4.3 & 3.9 & \pm 4.2 & -2.7 & \pm 2.2 \\
& P6 & -1.0 & \pm 4.5 & 1.2 & \pm 4.0 & -0.8 & \pm 2.2 \\
& P7 & -1.2 & \pm 4.3 & 1.2 & \pm 3.9 & -2.3 & \pm 2.8 \\
& P8 & -2.3 & \pm 4.2 & -0.8 & \pm 4.0 & -2.6 & \pm 2.8 \\
\hline
\end{tabular}

\section{Conclusion and Recommendations}

This paper presented a full study of movements due to differential settlement for façade points of some building in Fayoum city, Egypt. First, the technique used for monitoring was introduced. Then, the used mathematical approach was presented. Afterwards, experimental work was conducted in order to monitor the façade points of the building under study. Experiments were made in three phases. In the first phase the façade of building was monitored for 4.5 months (18 weeks). In this phase, starting from week 9 till week 18, outward movements perpendicular to façade direction were monitored. The amount of movement in this direction for any façade point was proportional to the height of this point. In addition, downward vertical movements (settlement) were monitored for the façade points observed in this phase. The amount of movements monitored in both perpendicular to façade direction and vertical direction increased by time. In the second phase, the recovery for monitored movements was done. The time for the second phase was 4.5 months. Finally, in the third phase the façade of building was monitored for 2 years. No significant movement neither in the façade direction, perpendicular to façade direction, nor in the vertical direction was monitored in this phase. Results showed that the introduced technique utilizing total station instrument provided a powerful and reliable tool for monitoring differential settlement of buildings.

Future researches will focus on developing a technique for instantly monitoring the behavior of buildings under dynamic loads. In addition, slope stability of road sides will be investigated utilizing total station instrument. Moreover, a technique for monitoring differential settlement of buildings utilizing close range photogrammetry will be developed. A similar technique for monitoring the behavior of buildings under dynamic loads utilizing close range photogrammetry will be developed. Finally, monitoring slope stability of road sides utilizing close range photogrammetry will be examined.

\section{Acknowledgement}

The project presented in this article is supported by Fayoum University and Yarmouk University. 


\section{References}

[1] Afeni, T. and Cawood, F. Slope Monitoring using Total Station: What are the Challenges and How Should These be Mitigated?. South African Journal of Geomatics, Vol. 2, No. 1, 2013.

[2] Baykal, O., Tari, E., Coskun, Z., and Erden, T. Accuracy of Point Layout with Polar Coordinates. ASCE, Journal of Surveying Engineering, Volume 131, Issue 3 (87 - 93), 2005.

[3] Eisenhart, L. Coordinate Geometry. New Dover Edition, Dover Publications, Inc., New York, USA, 2005.

[4] Kaloop, M., Beshr, A., and Elshiekh, M. Using Total Station for Monitoring the Deformation of High Strength Concrete Beams. 6th International Conference on Vibration Engineering (ICVE'2008), Dalian, China, 2008.

[5] Kananagh, B. and Mastin, T. Surveying Principles and Applications. 9th Edition, Pearson, USA, 2014.

[6] Mikhail, E. M. and Ackermann F. E. Observations and Least Squares. 2nd Edition, University Press of America, USA, 1982.

[7] RICS Guidance Note. EDM Calibration. 2nd Edition, Royal Institution of Chartered Surveyors (RICS), UK, 2007.

[8] Sokkia. Series 10 Set210 Electronic Total Station Operator's Manual. 4th Edition, Sokkia Co., Ltd., Japan, 2001.

[9] Thomas H. Slope Stability Prism Monitoring: A Guide for Practising Mine Surveyors. Master of Science Thesis in Mining Engineering, Faculty of Engineering and the Built Environment, University of the Witwatersrand, Johannesburg, South Africa, 2011.

[10] Uren, J. and Price, B. Surveying for Engineers. 5th Edition, Palgrave Macmillan, UK, 2010. 